"Note on the Theory of Ionization by Collision,', by W. P. Roop.

"Heat Losses from Incandescent Filaments in Air,', by L. W. Hartman.

"Magnetic Field Produced by Rotating Solid Conductors in a Magnetic Field.', (Read by abstract.) By S. R. Williams.

Many physicists accepted the invitation to attend a joint meeting of Section $A$, the American Mathematical Society and the American Astronomical Society Tuesday forenoon to hear addresses on "The Human Significance of Mathematics," by C. J. Keyser, Columbia University, and "The Work of a Modern Observatory,', by G. E. Hale, Mt. Wilson Observatory, Pasadena. Professor Hale's address was illustrated by interesting experiments on vortex motion.

Several instructive demonstrations were arranged by Professor E. P. Lewis, some of them at the request of Dr. Hale, where they could conveniently be examined between sessions. Among them were: Professor Stebbins's photoelectric cell for stellar photometry; the Zeeman effect with echelon grating, Fabry and Perot étalon and Lummer and Gehrecke plate; mercury fringes with Fabry and Perot interferometer; the amplitude of sound vibrations made visible by the forced vibrations of lycopodium particles.

Tuesday noon visiting physicists, astronomers and mathematicians and accompanying ladies were the guests of Professors E. P. Lewis, Haskell and Leuschner, at the luncheon at the Faculty Club, University of California.

Wednesday evening, immediately after the return from Stanford University, the physicists dined together at Jules Cafe, San Francisco. Attendance about thirty.

During the week many found opportunity to visit the exhibit of the National Bureau of Standards at the Panama-Pacific International Exposition, and some to make an excursion to the Lick Observatory at Mt. Hamilton, where the activities of the institution were explained by the astronomers in charge.

At the final session, a hearty vote of thanks was extended to the Pacific Coast Committee for the excellent arrangements made for the meetings, to the authorities of the University of California and of Stanford University for the accommodations provided and especially to the physics staff of the two institutions for the many courtesies extended by them.

$$
\begin{aligned}
& \text { A. D. CoLE, } \\
& \text { Secretary }
\end{aligned}
$$

\section{ANNUAL MEETING OF THE AMERICAN GENETIC ASSOCIATION}

THE American Genetic Association held its twelfth yearly meeting at Berkeley, Calif., August 2-6, in connection with the American Association for the Advancement of Science. More than three hundred persons attended the various conferences of the association.

The opening general meeting was held on Tuesday morning, August 3. President David Fairchild, of the U. S. Department of Agriculture, sent an opening address, in which he reminded the association that it had been organized to bring the message of genetics to the layman; to help the research worker to be more practical, and the practical breeder to be more scientific. He continued:

"The American Genetic Association is not primarily to promote research; it is to bring the biologist and the breeder together and help each to learn from the other. In my opinion, the greatest service we can do to genetics is to make its results available to the layman, and I hope to see the American Genetic Association more fully performing this service, year by year. I do not think we have fulfilled this obligation at all times as we should have done. It has been a constant temptation to coin new words, to invent methods of expressing our ideas in algebraical symbols, to present our researches in statistical form which made them a closed book to the practical breeder. All these methods are of use for the publication of original research, but in my opinion they must be supplemented by a simple account in plain English, for the benefit of those who are following our science, seeking its teaching for their own profit. They are calling on us to give them the light of science, and it is wicked to obscure this light by pedantry. I have no patience with those men of science who think their work loses dignity if it is put in simple English and made understandable to the layman. That was not the manner of Darwin, or of the other leaders of scientific thought in his generation; and if modern biology has less of a hold on the masses to-day than it had thirty years ago, if the teachings of biologists are less eagerly heard, I think we have ourselves largely to blame, and the custom which has insidiously grown on us, of describing our work in an esoteric terminology.

"I earnestly hope that the American Genetic Association can break away from this current, and stand forth as an exponent of real popularization of science. I believe the branch of science which 
we represent is second to none in the importance which it has for society, and I therefore look on the growing tendency to lift this above the layman's comprehension as a calamity, in which I hope the Journal of Heredity will have no share."

Dr. Herbert J. Webber, of the University of California, who spoke on "Science in the Practise of Plant Breeding," remarked that the effeet of the rediscovery of Mendel's Laws had often been over-emphasized. It had clarified our views, but as a fact, the segregation of characters in the second filial generation of a cross was well-known to breeders previous to 1900 , and they used this knowledge constantly in their work. He emphasized the great opportunities offered to breeders by the immense number of possible combinations of unit characters, and declared that more geneticists should attack the great problem of the origin of variations-the fundamental problem of breeding, but one which most experimental breeders were neglecting. The pure line theory, he declared, offered a chance for reconciling the conflicting views of the selectionist and the hybridist. He urged that practical breeders should make themselves more familiar with morphology and cytology.

Rob R. Slocum, of the U. S. Department of Agriculture, presented a review of experimental work in poultry breeding, and declared that the results of this work did not materially modify the procedure which intelligent poultrymen had been accustomed to follow for many years. One of the greatest practical results of genetic research in poultry, he thought, was to encourage poultrymen to keep more accurate pedigrees of their fowls. His paper was illustrated by motion pictures.

E. D. Ball and Byron Alder, of the Utah Experiment Station, discussed the question "Is Egglaying in the White Leghorn a Unit Character?", The results of their experiments at Logan, Utah, during seven years showed them that the firstyear egg production of a hen is no reliable measure of what she will do in succeeding years, and that winter egg-production is not a proper measure of a hen's fecundity, being even more subject to environmental influences than yearly totals. They decided that no evidence hitherto presented by any one was adequate to answer the question whether egg-laying is a unit character.

Leon J. Cole and Frank J. Kelley, of the University of Wisconsin, described their experimental breeding work on dominant and recessive red in pigeons. The red color found in uniformly colored tumbler pigeons was found by Cole some years ago to be a simple Mendelian recessive to black. Another factor has been found, however, which has the capacity of altering the expression of black; so that birds carrying the factor for black, if they also carry this second factor, often have a distinct reddish appearance superficially resembling those individuals which are red because of the absence of black. This second factor is sexlinked.

W. S. Anderson, of the University of Kentucky, described his work in the investigation of horse breeding. Aside from the attack of such practical problems as sterility, he has investigated the lines of descent of the most famous American trotting stallions, and found that thousands "run out," to every one which shows on-breeding capacity. The importance of the dam was emphasized in this connection. Following Professor Anderson's paper, motion pictures of the horse breeding of the Bureau of Animal Husbandry, U. S. Department of Agriculture, were shown.

H. B. Frost, of the University of California, described mutation in Mathiola annua, a "Mendelizing", species, and reported on tests of pedigreeculture methods in Southern California.

B. O. Cowan, of Santa Monica, Calif., whose subject was "Inbreeding," concluded: "That inbreeding of live stock has brought very beneficial results can not be denied; that it is a source of danger is equally true; so if practised at all, it should be with the greatest discretion.",

R. Ruggles Gates, of the University of London, spoke on "Successive Duplicate Mutations." Nilsson-Ehle first found duplicate and triplicate factors for red in wheat. Some races were found to have a single factor, giving only ratios 3 red: 1 white, others had two factors and hence gave also 15:1 ratios, while still others gave also $63: 1$ ratios and hence possessed three factors. It is suggested that this condition originated through mutation or chemical change having first taken place in one chromosome or pair of chromosomes. This gave the $3: 1$ condition. The duplicate condition arose from this afterwards, either through a similar change in another chromosome, or more probably by a mechanical re-mating of the chromosome pairs, thus giving 15:1 ratios. OEnothera rubricalyx similarly originated as a monohybrid through a chemical change in a chromosome, but some of the later generations have become dihybrid (giving 15:1 ratios) by a re-mating of the chromosomes. This rearrangement probably occurs at the time of fertilization rather than during meiosis. 
In a second paper, Dr. Gates considered the modification of characters by crossing. Many writers hold that Mendelian characters always come out of a cross unmodified, although work by Davenport and by Castle and Phillips indicates that such is not always the case. A crucial instance of the modification of a character by crossing was furnished by various hybrids of Enothera rubricalyx and $C E$. grandiflora. In the $\mathrm{F}_{2}$ of such crosses the red character $R$ of the rubricalyx buds usually splits out sharply, but a few plants were intermediate in pigmentation, and in $F_{3}$ these bred true to the intermediate condition. Further, in (rubricalyx $\times$ grandiflora) $\times$ grandiflora, the depth of pigmentation of $R$ plants is greatly diluted, though splitting takes place if the seed parent is heterozygous for $R$. The segregation is explained by the meiotic separation of the chromosome pairs. The dilution probably results from an inhibiting effect of the grandiflora chromosomes or perhaps from a modification of the $R$ chromosome of $Q E$. rubricalyx.

A. D. Shamel, of the U. S. Department of Agriculture, spoke on the origin and development of the Washington navel orange, which he believes originated at Bahia, Brazil, nearly one hundred years ago, as a bud sport from a Portuguese variety. After a description of orange culture at Bahia and the introduction and dissemination of this variety in the United States, by the U. S. Department of Agriculture, Mr. Shamel described the origin of a number of distinct types in southern California, through bud mutation. It is believed that growers have tended to select the least productive, but most vigorous, of these sports for propagation, and the industry has therefore tended to deteriorate. Careful limb-selection of buds is now being practised, and the yield per acre is being much increased, while the character of the fruit is being improved, on the average.

E. J. Kraus, of Oregon Agricultural College, discussed self-sterility among orchard fruits. Careful observations have shown that poor produetion is often due to self-sterility, and that in general every variety must be tested, to find whether its own pollen is sufficient or whether it requires cross-pollination. If the latter proves to be the case, it must be tested with as many varieties as possible, to find under what conditions it succeeds best. The Oregon station has worked out detailed treatment for many of the leading varieties in its region.

In a second paper, Mr. Kraus took up the ques- tion of somatic segregation, as shown in certain varieties of pear.

The eugenics section met on the afternoon of August 3, in joint session with the American Social Hygiene Association and the Eugenies Research Association, David Starr Jordan presiding. The program, which was entirely furnished by the American Genetic Association, follows:

Irving Fisher, of Yale University, "Eugenies and Sociology.' Professor Fisher discussed the mores, in their relation to eugenics, expressing a belief that the ideals of eugenies would come in some measure to be a substitute for the mores, as a criterion of morality and true value, when tho race became more enlightened. At present, an action, or an institution or custom, is held to be desirable or undesirable, according as it does or does not agree with the folkways, the inherited, almost instinctive traditions of the race. In the future, people will rather ask, "Is its effect eugenic?,

Wilhelmine E. Key, of the State Training School, Polk, Pa., presented in abstract a paper on "Creating a Eugenic Conscience." She set forth conclusions based on three years of inquiry concerning eugenic ideals in all social grades. Study of extensive networks shows the operation of a fairly well-defined conscience to cut off degenerative lines and by the principle of segregation to enhance the efficiency of the better lines, in various directions. Even the embryo conscience, as illustrated by amusing instances, has worked toward this end. The rôle of eugenic laws should be to hasten the elimination of bad stock, rather than to interfere with the free choice of the average young man and woman. Too great stress on ideal fitness gives us the ingrowing eugenic conscience. It is here that feminism shows its baneful effect. Here, as elsewhere, the problem of right conduct is conditioned on right instincts. Just as current thought is becoming imbued with scientific conceptions, so we may expect that gradually the recognition of such principles as that of segregation in individual pedigrees, will lead to free conscious selection along a multitude of able lines. This will give predominance to the best-endowed strains, insure manifold variety and solve many of the problems of practical eugenics without the necessity of legal enactment, so far as society in general is concerned.

David Starr Jordan, of Stanford University, speaking on "The Long Cost of War," emphasized the reversal of natural selection which takes place 
in warfare under modern conditions, and described the effect of this dysgenic factor on modern history.

Samuel C. Kohs, of the House of Correction, Chicago, taking as his subject "Eugenics and the Unconscious," warned those doing research in the heredity of human psychical traits that they were in many cases wholly superficial, and that, definition of the traits which they discussed was a prerequisite of intelligent treatment. He then described some of the recent studies of the unconscious mind, which indicate that many traits in children, which are commonly believed to have been inherited from parents, might in reality be due rather to impress on the unconscious mind, during the early years of childhood. Most of the work on the inheritance of mental characters in man is of doubtful value, he declared, because of any one or more of the following reasons:

1. Inaccurate tools with which to measure the ability or capacity.

2. Amateur field workers.

3. The use of the questionnaire method.

4. Where more than one field worker was necessary for obtaining the data, the differences in the individual standards of the field workers vitiated the results.

5. Being told for what to look, and possessing the popular conceptions regarding the inheritability of all sorts of traits, it is only just to assume that many of the assistants very easily found what was not there.

6. The study of character and personality is still in its infancy. To assume that certain peculiarities are due to the presence or absence of specific determiners can, in our present state of knowledge, hardly be substantiated by actual facts.

7. Some students approach the inheritance of mental traits too much from a biological point of view, and therefore go astray.

A. J. Rosanoff and Helen E. Martin, of the Kings Park State Hospital, Long Island, N. Y., submitted a preliminary report of a study on the offspring of the insane, which indicates that the forms of insanity considered behave as Mendelian recessives.

Ethel H. Thayer, of the Mendocino State Hospital, Talmage, Calif., described some of the cacogenic problems of California. She mentioned that the state sterilization law is now almost inoperative, because defectively drawn so that it can not be applied to the feeble-minded, the most important of the cacogenic classes which come under its scope.
Surgeon W. C. Billings, of the U. S. Public Health Service, Angel Island (San Francisco), Calif., described in some detail the administration of the immigration laws at California ports. Nearly all the immigrants are Asiatics, and therefore offer little of importance to eugenics, because marriages between them and the white population of the United States are extremely rare.

Walter B. Swift, in charge of the 'Voice Clinic of the Boston State Hospital, spoke on the possibility of voice inheritance. He discussed the inheritance of bone forms and body shapes as a basis upon which to build. The transmission of bone cavities as a further foundation. Consideration of the Indians" "high cheek bones" and the straight front nose of the Greek. The equine nose as found in the Jew. Such transmissions of bony exteriors-as an indication that cavities they contain are also inherited at least in some measure. If cavities are inherited then vocal elements based upon cavity formation for their fundamental qualities and overtones may also possibly be transmitted. Evidence from other sources. Illustrative cases.

The plant breeding section met all day on August 5, hearing the following papers:

Ernest B. Babcock, University of California, described walnut mutant investigations. "In 1912 I discovered an apparently normal tree of the California black walnut which annually bears a good crop of nuts, most of which when planted produce typical black walnuts, but a few of which produce a new type of walnut which I have named quercina because of its general resemblance to a smallleaved oak. This tree is probably the only perennial mutating individual accessible for experimentation. By using root-tips from these two types of seedlings we have ascertained the number of chromosomes characteristic of each and that the number is the same for both, thirty-four. Hence the mutation must be due to some other cause than a change in chromosome number. Breeding experiments are under way which may throw light on the nature of this mutation.",

L. D. Batchelor, University of California, explaining problems in walnut breeding, pointed out that most of the Persian (English) walnut groves of California are composed of seedlings, and that these must be worked over to the best strains, if the industry is to have its maximum efficiency.

Howard Gilkey, of the University of California, emphasized the need for breeding ornamentals that would meet the landscape gardener's requirement of definite types of form. 
Francis E. Lloyd, of McGill University, described his study of the Japanese persimmon, in which he found the presence of an emulsion colloid, which when it coagulated not only fixed the tannin, thus making the fruit palatable, but also caused a change in color of the flesh. In a second paper on "Intra-ovarial Treatments: Methods and Results," he said: "In pursuance of earlier investigations, and in the hope of reaching the eggcell directly by means of reagents which might possibly permanently disturb the germ-plasm, Torenia Fourneri has been studied. In spite of the protuberant embryo-sac, bringing the eggapparatus into a position of apparently maximum exposure, its position in contact with the placenta, together with other mechanical relations, precludes the object sought. The course of reagents (using methylene blue as a criterion) injected into the placenta is essentially identical with that earlier described for Scrophularia (Carn. Inst. Wash., Ann. Rep. 1914, p. 77). It has further been discovered that the mutual adjustments of the elements of the egg-apparatus and embryo-sac, which show a diffusion pressure equivalent to that of a $0.1 \mathrm{~N} \mathrm{KNO3}$ solution, are so delicate that access to tap-water is followed by bursting of the synergidæ and partial extrusion of the hydrocellulosic beak material, thus precluding the use of dilute watery solutions in immediate contact with the embryo-sac."

Sarkis Boshnakian, of Cornell University, described a new checkerboard method of representing Mendelian segregation, and gave a coefficient of squarehead form necessary for the statistical study of density in wheat.

W. B. McCallum, of San Diego, Calif., described the cultivation of several million plants of guayule (Parthenum argentatum), a Mexican plant which produces rubber. Although regarded as a single species, the plant has been found to have at least 125 forms, varying widely and all breeding true.

E. F. Gaines, Washington State Experiment Station, gave a brief account of results obtained by crossing wheats and barleys differing in two or more unit factors. Both dominance and lack of dominance have been secured in different cases, and one case of triplicate identical factors, cumulative in effect, was reported.

C. C. Vincent, Idaho Experiment Station, made a preliminary report on apple-breeding projects at that station. He told of the need of new varieties and described some thousands of crosses that have been made.
H. E. Knowlton, of Cornell University, describing studies in pollen germination with special reference to longevity, reported that pollen of the snapdragon (Antirrhinum majus) remained viable longest when kept at low temperature. Pollen stored at $-17^{\circ}$ to $-23^{\circ} \mathrm{C}$. for six weeks gave a fair percentage of germination in sugar solution, and moreover some of the flowers pollinated with it produced seeds.

Arthur W. Gilbert, Cornell University, "Color Inheritance in Phlox drummondi." "The following unit characters were found in the four varieties of Phlox drummondi that were used in these experiments: (1) A dark eye factor producing a dense coloration at the center of the flower. This was dominant over its absence, the white eye, which was exhibited in more or less of a definite pattern. (2) A blue factor. (3) A red factor. (4) An intensifying factor which determines the degree of pigmentation of the reds. (5) A yellow factor which acts only in the presence of the eye factor. The reds and blues are cell-sap colors, and the yellow is due to the presence of yellow chromoplasts."

Alfred C. Hottes, of Cornell University, discussed the practical hybridization of the gladiolus. It is a genus of about one hundred and thirty species, mostly natives of South Africa, a few from Europe. Approximately fifteen species have been cultivated or used in hybridization, so that this flower offers an excellent example of a flower improved by the incorporation of a number of species. The work has been carried on chiefly without reference to laws of inheritance; each species has transmitted to some hybrid a desirable feature which has been selected and impressed upon other hybrids.

George F. Freeman, of the University of Arizona, "Inheritance of Quality in Wheat." A number of recent investigators have declared that wheat quality is dependent on environment, and that the breeder could not control it. Careful review of all the work done shows this conclusion io be erroneous. Qualitative factors in wheat are to a large degree dependable and controllable.

John W. Gilmore, of the University of California, illustrated the wide variability of rye grasses and told of the possibilities for the practical breeder.

George L. Zundel, Cornell University, spoke on disease resistance in celery. Preliminary experiments were carried on at Cornell University by the writer to test the relative susceptibility of varieties of celery to the fungus Septoria petroselini Desm. var. apii Br. et Cav. No variety was 
found to be resistant to the fungus, but individual plants were found that were nearly immune. Since the celery flower is self-pollinated a method for future work is at once suggested, e. $g$., the selection of the immune plants as parents upon which to build immune strains of celery.

In a second paper, Mr. Zundel discussed the evolution of celery. Celery has been known to mankind for centuries. The Greeks and Romans used it mostly as a medical plant. They attributed to it great curative powers. Its native habitat is given as ranging from sweden to the Mediterranean and into British India. It is known botanically as Apium graveolens L. The early English name for celery was smallage and later it was known as salary. The Greeks called it Elioselinon or marsh parsley. Abercombie, in 1778, gives the first list of named varieties of celery. He gives four varieties, all of which originated on the large estates of titled gentlemen. Celery was at this time regarded as a luxury for the tables of titled gentlemen. The introduction, about 1883, of the Golden Self Blanching and White Plume celery revolutionized the celery industry of America.

G. P. Rixford, of the U. S. Department of Agriculture, told of the pistachio nut, which he believes will become a crop of some importance in parts of the south and west.

C. O. Smith, of the University of California, gave particulars of a method of inoculating plants to determine their comparative resistance to disease, in breeding work.

Frank S. Harris and J. C. Hogenson, Utah Agricultural College, discussed some correlations in sugar beets. It was found that the larger beets had the smaller sugar content; a number of other correlations were cited, which facilitate beet breeding.

G. N. Collins and J. H. Kempton, of the U. S. Department of Agriculture, described a bigeneric grass hybrid (Tripsacum dactyloides $\times$ Euchlcene mexicana) which shows no trace of the influence of the seed parent. Some reasons were given for thinking that it is not parthenogenetic.

W. A. Setchell and T. H. Goodspeed, of the University of California, conducted the meeting on a tour of their tobacco-breeding experiments.

At the closing general session of the association, Friday afternoon, August 6, Mrs. Myrtle Shepherd Francis, of Ventura, Calif., related her experience in breeding double seeding Petunias, and exhibited specimens.

H. Hayward, Delaware Experiment Station, spoke on inbreeding. Pearl's method for measur- ing accurately the degree to which an animal is inbred has caused a revision of many ideas on the subject. It has been found, for instance, that some of the famous sires of Bates, Booth and the Collings, were not nearly as much inbred as is popularly supposed. Breeding experiments with pigs, conducted at the Delaware station under careful control, have satisfied the speaker that when inbreeding is carried beyond a certain point, deterioration is inevitable. It is difficult to fix any arbitrary point, however, as the limit of safety.

Isabel MeCracken, of Stanford University, described Mendelian breeding experiments with silkworms.

J. H. Kempton, of the U. S. Department of Agriculture, described the result of a long series of breeding experiments with maize.

Albert F. Etter, of Briceland, Calif., told of his work in strawberry breeding, in which he has crossed commercial varieties with the beach strawberry of the Pacific coast, with the alpine species, and others. Plants much more resistant and productive than any present commercial variety have been obtained, and the berries offer a wide range of desirable commercial characters.

C. L. Redfield, of Chicago, defended his theory of dynamic evolution, maintaining that such functional qualities as speed in race horses, or milkproduction in cows, are developed by work and that the results of this development are then transmitted to the offspring. He declared that no single instance has ever been cited where this rule was violated.

C. L. Lewis, of the Oregon Agricultural College, speaking on plant-breeding problems of the Pacific Coast, declared it was a mistake to think there were plenty of good varieties of fruit already in existence; that in nearly every field the genetist was needed. He cited many cases to prove his point.

It was decided to continue holding the meetings of the American Genetic Association in connection with those of the American Association for the Advancement of Science. A committee headed by Herbert J. Webber and comprising R. Ruggles Gates, George H. Shull, W. E. Castle, Raymond Pearl, H. S. Jennings and Paul Popenoe, was appointed on nomenclature, with the particular request that it consider suitable definitions of inbreeding and linebreeding, which could be agreed on by genetists and practical breeders, and relieve the confusion which now attends the use of these two words.

Paul Popenoe, Secretary pro tem. 